\title{
Research on the Impact of Different Amount of Subsidy with Regard to Overcapacity: Evidence from Steel CO. in China
}

\author{
Xinxiang Mei ${ }^{1,}$,, Xi Peng ${ }^{2, b}$ \\ ${ }^{1}$ School of Law and Economics, Chongqing University of Science and Technology, Chongqing \\ 401331, China; \\ 2 Institute of Free Trade Zones, Sun Yat-Sen University, Guangzhou 510000, China. \\ a317692153@qq.com, b286917123@qq.com
}

\begin{abstract}
Government subsidy have an important impact on the production capacity of steel enterprises, it is yet unclear whether they reduce or aggravate enterprises' overcapacity. We take the firm-level data of steel enterprises from 1998 to 2014 as a sample, the methods of Propensity score matching (PSM) and Difference-in-Difference (DID) are used to address the impact of government subsidy on overcapacity. The results show that government subsidy have not a generally significant impact on the overcapacity of enterprises, since the different levels of government subsidy on overcapacity has offset each other. Low-level subsidy has no significant impact on the overcapacity. The effect of medium-level subsidy is positive and statistically significant. While, the coefficient of the huge-level subsidy is significantly negative, indicating that enterprises with huge-level subsidy have more serious overcapacity. Furthermore, Mediation model is applied to provide strong evidence that rent-seeking investment and the weakening of research and development (R\&D) incentives are the important channels for the huge-level subsidy curbing overcapacity.
\end{abstract}

Keywords: subsidy, overcapacity, rent-seeking, R\&D investment.

\section{Introduction}

China's steel expansion fueled the global sector once again in a state of overcapacity. This expansion, predominantly, caused by the subsidy policy. As one of the most important basic raw material industries in China, the iron and steel industry is highly valued by both central and local governments. The establishment and development of steel enterprises have always been inseparable from government support, even at the expense of other industries [1]. When demand is high, government's response is to give subsidy support to expand market share; when demand is low, government's response is to give subsidy support to remove excess capacity. Both production promotion subsidy policies and structural adjustment subsidy policies will trigger new investments and further reduce steel capacity utilization leading to overcapacity [2].

Although government subsidy is an important external cause of overcapacity, the internal reasons for enterprises actively to retain excess capacity mainly include: smoothing demand [3-4], reducing adjustment costs [5-6], defending against potential competitors [7-8], or just unable to overcome the exit barrier [3,9]. All of internal reasons also affect the motivation for enterprises to seek subsidy, which will lead to two problems in sample selection: the first one is the selection bias, which is caused by the non-observed factors; the second one is confounding bias, which is caused by the nonrandomness of government subsidy, for the purpose of social responsibility, local government may give greater amount of subsidy to enterprises with serious overcapacity to avoid its closure. In order to eliminate the above two biases, PSM-DID method is used to match the subsidized enterprises (treatment group) from the non-subsidized enterprises (control group) [10]. After matching, the control group enterprises can represent the overcapacity of the subsidized enterprises without government subsidy [11].

Yet, there is little evidence on how different amount of subsidy influence the overcapacity except Diebold \& Howell [12] proposing to consider the general impact of subsidy on steel capacity utilization. Considering the steel industry has the characteristics of high capital intensity, long expected return period, and high asset specificity [13], introducing advanced production lines needs more upfront capital support. If the subsidy is offered, it can help enterprises overcome the financial 
constraints of removing outdated equipment and introducing advanced equipment so as to improve the capacity utilization [12]. However, the remove of overcapacity or the closure of ineffective steel enterprises by local governments means that fiscal revenues are reducing, a large number of unemployed workers are generating, and local industrialization levels are declining. Governments need to bear huge social resettlement costs and unstable risks. For the purposes of political promotion, social security, and industrial development, government subsidy may be provided to maintain the uneconomic steel enterprises continuing production or survival, rather than invest on capacity adjustment project in that the project is high-risky. In this case, no matter how much the amount of subsidy is, it will not be used to improve capacity utilization, or even be used to exacerbate overcapacity. Therefore, the general impact of government subsidy on capacity utilization maybe uncertain.

Our aim is to identify the causal relationship between government subsidy and capacity utilization, and further to verify the impact of different amount of subsidy with regard to capacity utilization. This paper divides the amount of subsidy into low-level, medium-level, and huge-level by 50, 75, and 100 quantile values, it is found that low subsidy cannot provide sufficient funds for enterprises to adjust production capacity or invest on $R \& D$, so it has no impact on the capacity utilization of enterprises; while medium government subsidy means providing enterprise sufficient funding, which is conducive to increasing capacity utilization. However, huge-level subsidy has further worsened the overcapacity of steel enterprises.

Why does the huge-level subsidy worsen the capacity utilization of steel enterprises? From the perspective of profit maximization, when the amount of government subsidy is greater than the enterprise adjustment cost or sunk cost, enterprises may remove the backward excess capacity [6,9], thereby capacity utilization will be increased. While if government subsidy is less than the enterprise adjustment cost or sunk cost, then government subsidy may be regarded as the production capacity subsidy, which reduce the cost of holding excess capacity, and dump it to foreign markets at a low price [14], this means excess capacity is still accumulating. However, when the amount of subsidy is much greater than the cost of removing excess capacity, the capacity utilization of steel enterprises may deteriorate further. This is because: huge government subsidy, as part of the company's nonoperating income, will not only weaken the company's strong incentives to adjust overcapacity, which is good for improving the capacity utilization [15-16], but also encourage enterprises to obtain huge government subsidy through rent-seeking investment [17-18].

In China, the amount of subsidy received by steel enterprises is not only related to the operating conditions of enterprises, but also related to rent-seeking [18]. On the one hand, Lenway [19] founds steel firms that lobby congress for protection tend to be larger, older, less diversified, and less profitable than non-lobbyers. Such lobbyers are lack of risk-taking and unable to provide sufficient funds for R\&D innovation. Murphy [20] pointed out that in developing countries, corporate capital is usually used for trade rather than for long-term $R \& D$ investment. The reason is that for $R \& D$ enterprises, if the R\&D project are successful, innovation profits will be divided; if the project fails, the innovator bears the cost of research and development. Obviously, the company lacks the incentives for R\&D investment. On the other hand, for the local GDP and the promotion of officials, the collusion between government and enterprises has become a common phenomenon in the steel industry, and the probability of enterprises being punished for rent-seeking behavior is extremely low. Once rent-seeking investments are made and political connections are established, enterprises are more likely to continue to pursue rent-seeking investments, and rely on rent-seeking rather than through R\&D activities to maximize profits [17]. The marginal rent-seeking cost is relatively low in the subsequent rent-seeking activities, but the total cost of rent-seeking investment is still gradually increasing. This part of non-productive expenditures has squeezed investment funds that can improve capacity utilization.

This paper takes the rent-seeking cost and the proportion of $R \& D$ investment as the intermediate variables to analyze the transmission mechanism of overcapacity caused by the huge-level subsidy from the following two ways. First, the huge-level subsidy induces the enterprise to invest on rentseeking, which squeezing the funds good for improving the capacity utilization, that's why it worsens 
the overcapacity; secondly, enterprises can obtain huge-level subsidy income through rent-seeking, which obviously weakens the motives to obtain excess profits through R\&D investment.

The paper proceeds as follows: in the next section, we describe and processes the detailed data on enterprises' subsidy, capacity utilization and other characteristics variables. Then we preliminary test the differences of capacity utilization between subsidized and non-subsidized enterprises; Section3 shows the PSM matching results, and uses the DID method to estimate the impact of low-level, medium-level and huge-level subsidy on the capacity utilization; Section4 verifies the intermediary effect of government huge-level subsidy on capacity utilization: huge-level subsidy has caused overcapacity by rent-seeking and weakening R\&D incentives. Section5 is the conclusion

\section{Econometric Model}

\subsection{Firm-level Data.}

The data comes from the China Industrial Enterprise Micro Database 1997 through 2015. Firstly, we select the enterprises with a two-digit industry code of 32, that is, steelmaking, ironmaking, ferroalloy smelting, and steel rolling processing, a total sample inclusion of 37,800 enterprises are obtained. Secondly, we delete observations if any of the following rules are satisfied [21]: (1) one of the major financial variables (such as total assets, net fixed assets, sales, industrial output) is missing;(2) the enterprises have less than 8 employees; (3) the total assets less than the current assets, total fixed assets and net assets of fixed assets, so as to in accordance with the GAAP principle. (4) enterprises' opening year is after 2015 and only one year. The final sample contains 13024 observations.

Another challenge in sample processing is the choice of observation period. In 2004, as the watershed of central macro-control in China, it was marked by the famous "Tie Ben Event" in Changzhou, Jiangsu Province. In fact, the macro-control began at the end of 2003 and was further strengthened in 2004. The General Office of the State Council has successively issued < Notice of Development and Reform Commission and other departments about suppression of blind investment in the steel electrolytic aluminum cement industry $>$ (No. [2003]103), and <Notice of General Office of the State Council on Carrying out Special Inspections and the Implementation of the Spiritual Situation of the Central Economic Work Conference $>($ No. [2004] 2) in order to curb blind investment, low-efficient redundant construction, and clearly requiring that the industries of steel, electrolytic aluminum and cement must be cleaned and inspected.

Therefore, if the enterprise is subsidized for the first time during 2004-2008 period, then it is regarded as treatment group. If enterprise has never obtained any subsidy during 1998-2014 period, then it is regarded as control group. We take six years as an observation period, the first observation period is 1998-2003, and the second one is 2009-2014. The purpose of this paper is to examine whether any changes in the capacity utilization of the first-time subsidized enterprises between the first observation period (1998-2003) and the second observation period (2009-2014) are significantly different from those of the control enterprises

\subsection{PSM Matching.}

our sample is divided into four sub-samples by the dummy variables $d s u b=\{0,1\}$ and $d t=\{0,1\}$ : treatment group before obtaining subsidy, treatment group after obtaining subsidy, control group before obtaining subsidy, and control group after obtaining subsidy. $d s u b=1$ if it is a subsidized enterprise, $d s u b=0$ if it is a non-subsidized enterprise, $d t=0$ if the year is before obtaining subsidy, and $d t=0$ if the year is after obtaining subsidy. Then, the logarithmic regression model is used to calculate the propensity score value, and according to the propensity score, the kernel matching is used to construct the counterfactual result of the subsidy enterprise in the case of no subsidy.

$$
\operatorname{logit}(\mathrm{dsub}=1)=\varphi(\operatorname{lntfp}, \text { age, size, fzbl, state, pfrate, kjd })
$$

where: 
$\operatorname{lntfp---the~growth~rate~of~the~enterprise's~productivity,~which~is~(measured~by~the~Olley-Pakes~(OP)~}$ method [22] (Olley\&Pakes, 1960);

age--- calculated by the current year minus opening year plus 1 ;

size--- the $\log$ of the industrial sales value (current price) divided by the industrial price index based on 1998;

$f z b l$--- the Ratio of total liabilities (current price) to total industrial output (current price);

state---denoting firm ownership, state $==1$ denotes the firm is non-state enterprise, otherwise, state $=0$;

pfrate---the profitability of the firm and is constructed as the operating profit divided by operating income;

$k j d$--- the capital per labor, measured as the ration of the total fixed assets of original price to the total employees.

Descriptive statistics on the enterprises' capacity utilization and the above covariates are provided in Table1. We can find that subsidized enterprises are quite different from non-subsidized enterprises. The subsidized enterprises are older and have higher debt ratio, profitability and capital per labor than non-subsidized enterprises, but they have smaller firm size, lower capacity utilization and productivity growth rate.

Table 1. Descriptive statistics of key variables in our benchmark specification

\begin{tabular}{cccccc|ccccc}
\hline \multirow{2}{*}{ Variable } & \multicolumn{4}{c|}{ subsidized enterprise } & \multicolumn{5}{c}{ non-subsidized enterprise } \\
\cline { 2 - 11 } & Obs & Mean & Std. & Min & Max & Obs & Mean & Std. & Min & Max \\
\hline cu & 2960 & 0.669 & 0.070 & 0.053 & 0.880 & 10064 & 0.673 & 0.064 & 0.429 & 0.819 \\
lntfp & 2960 & 1.702 & 0.968 & -2.142 & 4.619 & 10064 & 1.790 & 1.138 & -8.217 & 5.774 \\
age & 2960 & 20.104 & 10.495 & 6 & 55 & 10064 & 18.017 & 9.809 & 6 & 93 \\
size & 2960 & 17.020 & 13.000 & 2 & 30 & 10064 & 19.893 & 12.773 & 1 & 30 \\
fzbl & 2960 & 0.680 & 0.349 & 0 & 4.123 & 10064 & 0.615 & 0.338 & 0 & 3.384 \\
dummy-state & 2960 & 0.166 & 0.372 & 0 & 1 & 10064 & 0.107 & 0.309 & 0 & 1 \\
pfrate & 2960 & 0.006 & 0.201 & -3.576 & 0.749 & 10064 & -0.014 & 0.648 & -33.185 & 0.848 \\
kjd & 2960 & 3.973 & 1.011 & 0.451 & 6.517 & 10064 & 3.720 & 1.160 & 0.347 & 7.794 \\
\hline
\end{tabular}

\subsection{DID Estimation.}

Based on the propensity score, we get a sample with the same attributes except the subsidy, then we use DID method to identify the impact of subsidy on capacity utilization.

$$
\mathrm{cu}_{i t}=\alpha_{0}+\alpha_{1} d s u b_{i t}+\alpha_{2} d t_{i t}+\alpha_{3} d s u b_{i t} \times d t_{i t}+\alpha_{4} X_{i t}+v_{j}+v_{k}+\varepsilon_{i t}
$$

Our dependent variable in (2), $c u_{i t}$ denotes the capacity utilization of firm $i$ in year $t$, we defined capacity utilization as he ratio of actual output to potential output, where the potential output is at the cut-off point of the short-term cost curve and the long-term average cost curve under the condition of capital stock constraints, it is calculated by using the transcendental logarithmic cost function [2325]. The lower the capacity utilization, the more serious the overcapacity.

$X_{i t}$ denote a matrix of the above matching variables measuring the size, age, liabilities, profits, ownership of enterprise. The coefficient $\alpha_{3}$ is the treatment effect we are concerned about, $\alpha_{3}=\mathrm{E}(\Delta \mathrm{cu} \mid \mathrm{dsub}=1)-\mathrm{E}(\Delta \mathrm{cu} \mid \mathrm{dsub}=0)$, denoting Represents the difference in capacity utilization between the treatment and control groups. $v_{j}$ is the firm fixed effects controlling for any unobserved differences in trends common to a particular steel firm $v_{k}$ are the regional fixed effects controlling for unobserved differences in trends common to a region across all its steel products. $\varepsilon_{i t}$ is the white noise.

In order to further verify the impact of different amounts of government subsidy on the capacity utilization. Firstly, the subsidy income per unit of output value is used as a measure of the intensity of subsidy. Then, we take 50, 75, and 100-digit values as the threshold for dividing the income of 
low-level, medium-level, and huge-level subsidy. According to this, the following empirical specification is estimated:

$$
\begin{aligned}
\mathrm{cu}_{i t}=\beta_{0}+\beta_{1} d s u b_{i t}+\beta_{2} d t_{i t} & +\beta_{3} d s u b_{i t}^{1} \times d t_{i t}+\beta_{4} d s u b_{i t}^{2} \times d t_{i t}+\beta_{5} d s u b_{i t}^{3} \times d t_{i t} \\
& +\beta_{6} X_{i t}+v_{j}+v_{k}+\varepsilon_{i t}
\end{aligned}
$$

The variables $d s u b_{i t}^{1}, d s u b_{i t}^{2}$, and $d s u b_{i t}^{3}$ denote the low-level, medium-level and huge-level subsidy received by treatment group, respectively, $\beta_{3}, \beta_{4}, \beta_{5}$ are estimated coefficients.

Table 2 shows the preliminary relationship between government subsidy and capacity utilization of steel enterprises. The capacity utilization rate of both the treatment group and the control group enterprises have been improved to different degrees after subsidy. However, the double difference score is -0.018 , which is significant at $5 \%$ level, indicating that the difference between the two groups is further enlarged after the subsidy. That is to say, after receiving the government subsidy, the capacity utilization of the treatment group decreased significantly compared with the control group, which means subsidy have reduced capacity utilization. In summary, the government subsidy has a positive impact on steel enterprises' overcapacity. Based on this preliminary conclusion, we also consider of other factors, such as lntfp, age, size, fzbl, state, pfrate, kjd, that affect the capacity utilization rate, and use PSM method to solve the non-random problem of samples, in order to get a more rigorous result of the influence of government subsidy on the capacity utilization.

Table 2. DID regression estimated results of the capacity utilization before matching

\begin{tabular}{c|ccc|ccc|c}
\hline \multirow{2}{*}{ Variable } & \multicolumn{3}{|c|}{ pre-subsidy } & \multicolumn{3}{c|}{ post-subsidy } & \multirow{2}{*}{ Diff-in-Diff } \\
\cline { 2 - 7 } & Treatment & Control & Diff(T-C) & Treatment & Control & Diff(T-C) & (T.041*** \\
\hline $\mathrm{cu}$ & 0.670 & 0.701 & $\begin{array}{c}-0.031^{* * *} \\
(0.007)\end{array}$ & 0.674 & 0.715 & $\begin{array}{c}-0.041^{* * *} \\
(0.004)\end{array}$ & $\begin{array}{c}-0.01^{* *} \\
(0.008)\end{array}$ \\
\hline
\end{tabular}

Notes: The values in () are robust standard errors; $* * * \mathrm{p}<0.01 ; * * \mathrm{p}<0.05 ;{ }^{*} \mathrm{p}<0.1$.

\section{Results}

\subsection{Matching Quality.}

Table 3 provides evidence that after matching, our treatment and control group for a range of enterprises' characteristics are well-balanced. The maximum deviation bias is 7.6, Standardized bias for virtually all observable variables is reduced to below $10 \%$, and in most cases below $5 \%$ level, this level is considered acceptable in the literature [26]. The $t$ test indicates that the observable characteristics after matching are not statistically significant, meaning that there are no systematic differences, that is, based on the above characteristics, we cannot infer the differences of capacity utilization among steel enterprises.

Figure 1 shows the nuclear density of the propensity scores of treatment group and control group before and after matching. Before matching, there is a big difference in the probability distribution of the propensity scores between treatment group and control group. After matching, the probability distributions of both groups are basically consistent in morphology, and the centers of gravity of the two groups are closer to each other than before matching, indicating that the difference about the observed characteristics of two groups is significantly reduced, furthermore, it indicates the matching quality is good. 
Table 3. Testing match quality of the propensity score matching

\begin{tabular}{|c|c|c|c|c|c|c|c|}
\hline \multirow{2}{*}{ Variable } & \multirow{2}{*}{ sample } & \multicolumn{2}{|c|}{ mean } & \multirow{2}{*}{$\begin{array}{c}\text { bias } \\
\%\end{array}$} & \multirow{2}{*}{$\begin{array}{l}\text { bias reduction } \\
\%\end{array}$} & \multicolumn{2}{|c|}{ t-test } \\
\hline & & treatment & control & & & $\mathrm{t}$ & $p>t$ \\
\hline \multirow{2}{*}{$\operatorname{lntfp}$} & Unmatched & -0.4633 & 0.1109 & -58.9 & \multirow{2}{*}{98} & -8.67 & 0 \\
\hline & Matched & -0.4633 & -0.2827 & 1.2 & & 0.15 & 0.884 \\
\hline \multirow{2}{*}{ age } & Unmatched & 0.1449 & 0.2190 & -46.1 & \multirow{2}{*}{90.8} & -6.8 & 0 \\
\hline & Matched & 0.1449 & 0.1698 & -4.2 & & -0.66 & 0.507 \\
\hline \multirow{2}{*}{ size } & Unmatched & 10.800 & 10.9900 & -14.9 & \multirow{2}{*}{70.8} & -2.19 & 0.029 \\
\hline & Matched & 10.800 & 10.7180 & 4.3 & & 0.58 & 0.56 \\
\hline \multirow{2}{*}{ fzbl } & Unmatched & 0.6808 & 0.3611 & 106.5 & \multirow{2}{*}{95.1} & 15.68 & 0 \\
\hline & Matched & 0.6808 & 0.5886 & 5.2 & & 0.87 & 0.385 \\
\hline \multirow{2}{*}{ state } & Unmatched & 0.1655 & 0.0046 & 60.2 & \multirow{2}{*}{87.5} & 8.85 & 0 \\
\hline & Matched & 0.1655 & 0.0721 & -7.5 & & -1.1 & 0.271 \\
\hline \multirow{2}{*}{ pfrate } & Unmatched & 0.0231 & 0.0523 & -35.2 & \multirow{2}{*}{97} & -5.19 & 0 \\
\hline & Matched & 0.0231 & 0.0318 & -1.1 & & -0.16 & 0.871 \\
\hline \multirow{2}{*}{ kjd } & Unmatched & 9.5872 & 8.9268 & 42.6 & \multirow{2}{*}{99.4} & 6.28 & 0 \\
\hline & Matched & 9.5872 & 9.3667 & -0.3 & & -0.03 & 0.973 \\
\hline
\end{tabular}
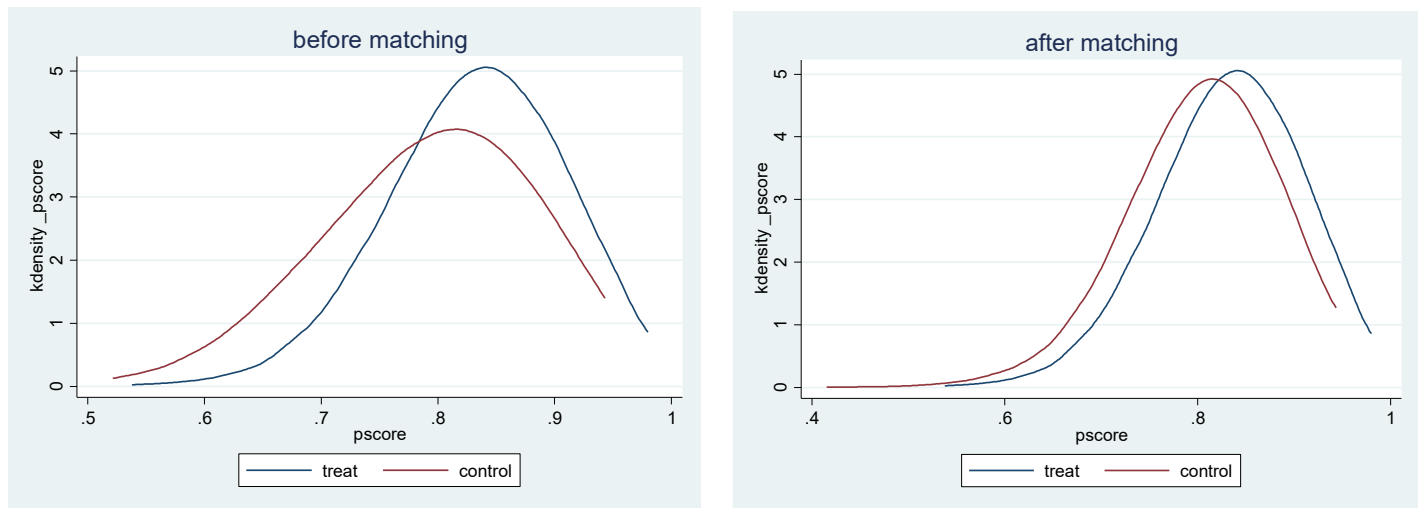

Figure 1. Nuclear density distribution of propensity scores

\subsection{Estimated Effects of Government Subsidy on Capacity Utilization.}

Table 4 provides DID regression results based on equation (2) and (3) for our sample 4 industries and 13024 observations from 1998 through 2015. Column(1)-(3) of Table 4 are the results of equation (2) estimated by stepwise regression. Column 1 can be viewed as our benchmark model. In Column (2) and (3), the estimated coefficients and significance levels of independent variables have not changed a lot, which indicates that regression results have better robustness. In Column (3), the coefficient on the $d s u b$ variables is 0.141 but not statistically significant at $10 \%$, indicating that the capacity utilization of the treatment group is not significantly higher than that of the control group in the initial year. The coefficient on the $\underline{d t}$ variables is 0.0614 and is statistically significant at $1 \%$, Statistical evidence for the capacity utilization of both groups improved over time are strong, which is consistent with the results of Table 2. The intriguing part is that the coefficient of the interaction term $d s u b^{*} d t$ is not significant, indicating that the overall impact of government subsidy on the overcapacity is not obvious. The possible explanation for this is that the government subsidy effect is related to the level of subsidy, and different amounts of government subsidy will offset each other.

In Column (4)-(6) of Table4, we examine whether the mutual offset effect of government subsidy on capacity utilization does existing by including three interaction terms $d u s b^{1 * d t} d u s^{2 * d t} d u s^{3 * d t}$. In column (6), variable $d u s b^{1 * d t}$ is not estimated to have a significant impact on the capacity utilization though the coefficient is negative, indicating that low-level government subsidy has no significant impact on the overcapacity. As mentioned earlier, both capacity adjustment and R\&D 
investment to remove excess capacity require long-term and large-scale financial support. Even if enterprises accept the low-level subsidy from the government, steel enterprises still lack sufficient funds to increase capacity utilization. Therefore, low-level subsidy has not significantly motivated enterprises to increase capacity utilization.

We find a positive coefficient on the $d u s^{2 *} d t$ variable, indicating that enterprises receiving moderate subsidy are interested in improving capacity utilization. This is because: improving capacity utilization often requires long-term and large-scale capital investment, moderate subsidy provide sufficient funds for capacity adjustment and R\&D investment, which in turn encourages enterprises to remove excess capacity and increase capacity utilization.

Table 4. PSM-DID estimates of the government subsidy on the capacity utilization

\begin{tabular}{|c|c|c|c|c|c|c|c|}
\hline \multirow{2}{*}{ Variable } & \multicolumn{3}{|c|}{ Base Specification } & \multicolumn{3}{|c|}{ Different Level of Subsidy } & \multirow{2}{*}{$\frac{\text { Robustness }}{(7)}$} \\
\hline & (1) & (2) & (3) & (4) & (5) & (6) & \\
\hline \multirow[t]{2}{*}{ dsub } & 0.0128 & 0.140 & 0.141 & 0.0014 & 0.0161 & 0.0136 & 0.0022 \\
\hline & $(0.140)$ & $(0.0910)$ & $(0.0913)$ & $(0.0123)$ & $(0.0190)$ & $(0.0193)$ & $(0.0031)$ \\
\hline \multirow[t]{2}{*}{$\mathrm{dt}$} & $0.0980 * * *$ & $0.0605 * * *$ & $0.0614 * * *$ & $0.1000 * * *$ & $0.0265 * *$ & $0.0297 * * *$ & $0.0434 * * *$ \\
\hline & $(0.0149)$ & $(0.0124)$ & $(0.0125)$ & $(0.0149)$ & $(0.0103)$ & $(0.0111)$ & $(0.0104)$ \\
\hline \multirow[t]{2}{*}{ dsub*dt } & -0.022 & -0.132 & -0.133 & & & & \\
\hline & $(0.140)$ & $(0.0912)$ & $(0.0915)$ & & & & \\
\hline \multirow[t]{2}{*}{$\mathrm{dsub}^{1 *} \mathrm{dt}$} & & & & -0.00267 & -0.0025 & -0.0013 & -0.0117 \\
\hline & & & & $(0.0182)$ & $(0.0135)$ & $(0.0135)$ & $(0.0127)$ \\
\hline \multirow[t]{2}{*}{$\mathrm{dsub}^{2 *} \mathrm{dt}$} & & & & $0.0447 *$ & $0.0600 * * *$ & $0.0600 * * *$ & $0.164 * * *$ \\
\hline & & & & $(0.0231)$ & $(0.0124)$ & $(0.0125)$ & $(0.0164)$ \\
\hline \multirow{2}{*}{$\mathrm{dsub}^{3 *} \mathrm{dt}$} & & & & $-0.0211 *$ & $-0.0283 * * *$ & $-0.0310 * * *$ & $-0.0383 * * *$ \\
\hline & & & & $(0.0121)$ & $(0.0100)$ & $(0.0106)$ & $(0.0099)$ \\
\hline \multirow[t]{2}{*}{$\operatorname{lntfp}$} & & 0.121 & 0.121 & & 0.115 & 0.103 & 0.110 \\
\hline & & $(0.265)$ & $(0.265)$ & & $(0.263)$ & $(0.263)$ & $(0.247)$ \\
\hline \multirow[t]{2}{*}{ age } & & $-0.0359 *$ & $-0.0360 *$ & & $-0.0343 *$ & $-0.0370^{*}$ & $-0.254 *$ \\
\hline & & $(0.0198)$ & $(0.0202)$ & & $(0.0201)$ & $(0.0204)$ & $(0.147)$ \\
\hline \multirow[t]{2}{*}{ size } & & $-0.0867 * * *$ & $-0.0866 * * *$ & & $-0.0867 * * *$ & $-0.0864 * * *$ & $-0.0771 * * *$ \\
\hline & & $(0.0034)$ & $(0.0034)$ & & $(0.0035)$ & $(0.0035)$ & $(0.0033)$ \\
\hline \multirow[t]{2}{*}{ fzbl } & & 0.0164 & 0.0163 & & 0.0051 & 0.0049 & 0.0180 \\
\hline & & $(0.0115)$ & $(0.0115)$ & & $(0.0042)$ & $(0.0042)$ & $(0.0182)$ \\
\hline \multirow[t]{2}{*}{ state } & & 0.0402 & 0.0427 & & 0.0314 & 0.0331 & 0.0092 \\
\hline & & $(0.0420)$ & $(0.0421)$ & & $(0.0424)$ & $(0.0424)$ & $(0.0380)$ \\
\hline \multirow[t]{2}{*}{ pfrate } & & $0.0081 * *$ & $0.0082 * *$ & & $0.0076^{* *}$ & $0.0077 * *$ & $0.0315^{* * *}$ \\
\hline & & $(0.0032)$ & $(0.0033)$ & & $(0.0033)$ & $(0.0033)$ & $(0.0118)$ \\
\hline \multirow[t]{2}{*}{ kjd } & & $0.0759 * * *$ & $0.0736^{* * *}$ & & $0.0741 * * *$ & $0.0711 * * *$ & $0.0628 * * *$ \\
\hline & & $(0.0161)$ & $(0.0162)$ & & $(0.0163)$ & $(0.0164)$ & $(0.0155)$ \\
\hline \multirow[t]{2}{*}{ Constant } & $1.413 * * *$ & $2.352 * * *$ & $2.344 * * *$ & $1.413 * * *$ & $2.368 * * *$ & $2.363 * * *$ & $2.278 * * *$ \\
\hline & $(0.008)$ & $(0.041)$ & $(0.044)$ & $(0.008)$ & $(0.042)$ & $(0.045)$ & $(0.043)$ \\
\hline $\begin{array}{l}\text { Region fixed } \\
\text { effects }\end{array}$ & No & Yes & Yes & No & Yes & Yes & Yes \\
\hline $\begin{array}{l}\text { Firm fixed } \\
\text { effects }\end{array}$ & No & No & Yes & No & No & Yes & Yes \\
\hline $\mathrm{R}^{2}$ & 0.0943 & 0.6355 & 0.6358 & 0.0980 & 0.6338 & 0.6338 & 0.4073 \\
\hline Sample size & 13024 & 13024 & 13024 & 13024 & 13024 & 13024 & 13024 \\
\hline
\end{tabular}

Notes: The value in () is the $\mathrm{t}$ statistic after correcting the heteroscedasticity; ${ }^{* * *} \mathrm{p}<0.01 ;{ }^{* *} \mathrm{p}<0.05$; $* \mathrm{p}<0.1$.

A negative coefficient and statistically significant on interaction term $d u s^{3 *} d t$ would indicate that huge-level government subsidy has weakened the company's intention to improve capacity utilization. We believe that the possible reasons for this result are as follows: first, the subsidy income received by the enterprise from the government is part of the total profit of the enterprise. If the government gives a huge amount of subsidy, it means the enterprise has obtained excessive profits from it, which 
may weaken the preference of the enterprise for capacity adjustment and R\&D investment to improve the capacity utilization. Secondly, in order to obtain huge-level subsidy, steel enterprises will actively bribery local government officials, which will result in high rent-seeking costs or "subsidy-seeking" investments. Such high cost or investments may squeeze a partial expenditure of capacity adjustment and R\&D investment, and it's harmful for the capacity utilization. Thirdly, often accompanied by huge government subsidy are social responsibilities, such as solving the local unemployment problems, this will be an excellent excuse to carry out the next round of rent-seeking investment and continuously retain excess capacity.

The control variables perform as follows: The effects of enterprises' size and age on the capacity utilization are negative and statistically significant with -0.0864 and -0.037 , respectively. The coefficient on the pfrate and kjd variables are positive and statistically significant, indicating that the capacity utilization is improved when the enterprise has a strong profitability or high capital per capita. Variables lntfp, state, $f z b l$ are not estimated to have a significant impact on the capacity utilization.

\subsection{Robustness to Alternative Observation Period.}

One concern with the regression is that if the observation period is changed, will the result be the same? In order to verify the robustness of the estimated results, we shorten the observation period to five years. Specifically, 1999-2003 is the first observation period, and 2009-20013 is the second observation period. Model (3) is estimated and the results are shown in column (7) of Table 4. We find that the impact of low-level, medium-level and huge-level subsides on capacity utilization is consistent with column (6) of Table 4. Overall, the estimated results are the same across different observation periods, suggesting that our results are not the result of cherry-picking results.

\section{Intermediary Effect: Why is Huge-Level Subsidy Harmful to the Capacity Utilization of Enterprises?}

In the previous section, our main finding is that medium subsidy is good to the capacity utilization, while huge-level subsidy is harmful to the capacity utilization, Then the question comes, why does the huge-level subsidy reduce the capacity utilization, and which factors have contributed to this result? According to the explanation in the regression, we construct an intermediate model to explore the possible mechanisms by introducing "rent-seeking costs" and "R\&D investment" as intermediate variable. We use the ratio of management expenses to total assets and the Ratio of R\&D expenditure to total sales to proxy for "rent-seeking costs" and "R\&D investment" variables, respectively.

Model (5) is the intermediary model with five equations: in the first equation, the dependent variable is the capacity utilization representing overcapacity in steel enterprises, the independent variable is the matrix of covariates. Mediator variables (the rent-seeking costs and R\&D investment) are the independent variables of the second equation and the third equation, respectively, and the independent variables of the two equations are the same as the first equation. In the fourth equation, the dependent variable is the capacity utilization, the independent variable contains both covariates and mediator variables.

$$
\begin{gathered}
\operatorname{cu}_{i t}=\alpha_{0}+\alpha_{1} d s u b_{i t}+\alpha_{2} d t_{i t}+\alpha_{3} d s u b_{i t} \times d t_{i t}+\alpha_{4} X_{i t}+v_{j}+v_{k}+\varepsilon_{i t} \\
\operatorname{rent}_{i t}=\alpha_{0}+\alpha_{1} d s u b_{i t}+\alpha_{2} d t_{i t}+\alpha_{3} d s u b_{i t} \times d t_{i t}+\alpha_{4} X_{i t}+v_{j}+v_{k}+\varepsilon_{i t} \\
\mathrm{RD}_{i t}=\alpha_{0}+\alpha_{1} d s u b_{i t}+\alpha_{2} d t_{i t}+\alpha_{3} d s u b_{i t} \times d t_{i t}+\alpha_{4} X_{i t}+v_{j}+v_{k}+\varepsilon_{i t} \\
\mathrm{cu}_{i t}=\alpha_{0}+\alpha_{1} d s u b_{i t}+\alpha_{2} d t_{i t}+\alpha_{3} d s u b_{i t} \times d t_{i t}+\text { rent }_{i t}+\mathrm{RD}_{i t}+\alpha_{4} X_{i t}+v_{j}+v_{k}+\varepsilon_{i t}
\end{gathered}
$$

Table 5 provides the regression results based on intermediary model (4). Column (1) of Table 5 is the estimated result of the first equation, which is the same as column (6) of Table 4. In column (2) we examine the effect of different amounts of subsidy on the rent-seeking investment, the case for huge-level subsidy increasing the rent-seeking expenditure of enterprises is supported by a positive and statistically significant coefficient on our $d s u b^{3 *} d t$ variable, indicating that in order to obtain high 
subsidy, enterprises have a strong incentive to seek rent from local governments by investing in manpower, material resources and financial resources. However, the estimated coefficient on this interaction term $d s u b^{1 *} d t$ is negative, it is statistically insignificant. Interestingly, a negative coefficient and statistically significant on variable $d s u^{2 *} d t$ would suggest that medium government subsidy have reduced the enterprises' rent-seeking expenses. The reason may be that moderate government subsidy encourage enterprises to improve their capacity utilization, which will prompt them to reduce their non-productive expenditures, such as the rent-seeking expenses.

Table 5. The mediating effect of huge-level subsidy on the capacity utilization

\begin{tabular}{|c|c|c|c|c|c|c|}
\hline \multirow[t]{2}{*}{ Variable } & \multirow{2}{*}{$\begin{array}{c}\begin{array}{l}\text { The First } \\
\text { equation }\end{array} \\
(1)\end{array}$} & \multicolumn{2}{|c|}{$\begin{array}{c}\text { Mediation effect } \\
\text { The Second \&Third } \\
\text { equation }\end{array}$} & \multicolumn{3}{|c|}{$\begin{array}{c}\text { The fourth equation estimated by } \\
\text { stepwise DID }\end{array}$} \\
\hline & & $\operatorname{Rent}(2)$ & $\mathrm{RD}(3)$ & (4) & (5) & (6) \\
\hline dsub & $\begin{array}{c}0.0136 \\
(0.0193)\end{array}$ & $\begin{array}{l}0.092 \\
(1.276)\end{array}$ & $\begin{array}{c}0.015 \\
(1.515)\end{array}$ & $\begin{array}{c}0.002 \\
(0.124)\end{array}$ & $\begin{array}{c}0.026 \\
(0.846)\end{array}$ & $\begin{array}{c}0.027 \\
(0.868)\end{array}$ \\
\hline $\mathrm{dt}$ & $\begin{array}{c}0.0297 * * * \\
(0.0111)\end{array}$ & $\begin{array}{l}0.154 * * \\
(2.166)\end{array}$ & $\begin{array}{l}0.020 * * \\
(1.990)\end{array}$ & $\begin{array}{l}0.027 * * \\
(2.047)\end{array}$ & $\begin{array}{l}0.027 * * \\
(2.112)\end{array}$ & $\begin{array}{l}0.029 * * \\
(2.288)\end{array}$ \\
\hline $\mathrm{dsub}^{1 * \mathrm{dt}}$ & $\begin{array}{l}-0.0013 \\
(0.0135)\end{array}$ & $\begin{array}{c}-0.038 \\
(-0.331)\end{array}$ & $\begin{array}{l}-0.010 \\
(-0.846)\end{array}$ & $\begin{array}{l}-0.010 \\
(-0.585)\end{array}$ & $\begin{array}{c}-0.003 \\
(-0.178)\end{array}$ & $\begin{array}{l}-0.002 \\
(-1.113)\end{array}$ \\
\hline $\mathrm{dsub}^{2 *} \mathrm{dt}$ & $\begin{array}{l}0.0600 * * * \\
(0.0125)\end{array}$ & $\begin{array}{l}-0.155^{*} \\
(-1.747)\end{array}$ & $\begin{array}{l}0.031 * * * \\
(14.947)\end{array}$ & $\begin{array}{l}0.037 * \\
(1.886)\end{array}$ & $\begin{array}{c}0.038 * * * \\
(3.387)\end{array}$ & $\begin{array}{c}0.035^{* *} \\
(3.101)\end{array}$ \\
\hline $\mathrm{dsub}^{3 *} \mathrm{dt}$ & $\begin{array}{c}-0.0310^{* * *} \\
(0.0106)\end{array}$ & $\begin{array}{c}1.475^{* * *} \\
(8.431)\end{array}$ & $\begin{array}{l}-0.020 * * \\
(-2.136)\end{array}$ & $\begin{array}{l}-0.027^{* *} \\
(-2.159)\end{array}$ & $\begin{array}{l}-0.021^{*} \\
(-1.779)\end{array}$ & $\begin{array}{l}-0.020^{*} \\
(-1.866)\end{array}$ \\
\hline Rent & & & & $\begin{array}{l}-0.369 * \\
(-1.715)\end{array}$ & & $\begin{array}{c}-0.376^{* * *} \\
(-8.580)\end{array}$ \\
\hline $\mathrm{RD}$ & & & & & $\begin{array}{c}0.088^{* * *} \\
(2.579)\end{array}$ & $\begin{array}{l}0.0001^{*} \\
(-1.903)\end{array}$ \\
\hline $\operatorname{lntfp}$ & $\begin{array}{c}0.103 \\
(0.263)\end{array}$ & $\begin{array}{c}0.924 \\
(0.517)\end{array}$ & $\begin{array}{c}0.484 * * \\
(1.973)\end{array}$ & $\begin{array}{c}0.098 \\
(0.298)\end{array}$ & $\begin{array}{c}0.030 \\
(0.097)\end{array}$ & $\begin{array}{c}0.029 \\
(0.092)\end{array}$ \\
\hline age & $\begin{array}{c}-0.0370^{*} \\
(0.0204)\end{array}$ & $\begin{array}{c}0.017 * * * \\
(7.866)\end{array}$ & $\begin{array}{c}-0.001 * * \\
(-2.226)\end{array}$ & $\begin{array}{c}-0.042 * * \\
(-2.065)\end{array}$ & $\begin{array}{c}-0.039 * * \\
(-2.010)\end{array}$ & $\begin{array}{l}-0.035^{*} \\
(-1.808)\end{array}$ \\
\hline size & $\begin{array}{c}-0.0864 * * * \\
(0.0035)\end{array}$ & $\begin{array}{c}0.148 * * * \\
(7.185)\end{array}$ & $\begin{array}{c}0.029 \\
(1.210)\end{array}$ & $\begin{array}{r}-0.086^{* * *} \\
(-27.189)\end{array}$ & $\begin{array}{c}-0.090 * * * \\
(-29.488)\end{array}$ & $\begin{array}{r}-0.091 * * * \\
(-29.477)\end{array}$ \\
\hline fzbl & $\begin{array}{c}0.0049 \\
(0.0042)\end{array}$ & $\begin{array}{c}0.040 * * \\
(2.309)\end{array}$ & $\begin{array}{c}-0.009 * * \\
(-3.006)\end{array}$ & $\begin{array}{c}0.006 \\
(1.474)\end{array}$ & $\begin{array}{c}0.005 \\
(1.113)\end{array}$ & $\begin{array}{c}0.004 \\
(1.078)\end{array}$ \\
\hline state & $\begin{array}{c}0.0331 \\
(0.0424)\end{array}$ & $\begin{array}{c}-0.132 * * \\
(-2.987)\end{array}$ & $\begin{array}{c}-0.001 \\
(-0.237)\end{array}$ & $\begin{array}{c}0.029 \\
(0.962)\end{array}$ & $\begin{array}{c}0.034 \\
(1.422)\end{array}$ & $\begin{array}{c}0.027 \\
(0.868)\end{array}$ \\
\hline pfrate & $\begin{array}{c}0.0077 * * \\
(0.0033)\end{array}$ & $\begin{array}{c}-0.139 * * * \\
(-2.061)\end{array}$ & $\begin{array}{c}0.115^{* * *} \\
(7.809)\end{array}$ & $\begin{array}{c}0.050 * * * \\
(4.258)\end{array}$ & $\begin{array}{c}0.204 * * * \\
(4.149)\end{array}$ & $\begin{array}{c}0.201 * * * \\
(4.094)\end{array}$ \\
\hline kjd & $\begin{array}{c}0.0711 * * * \\
(0.0164)\end{array}$ & $\begin{array}{c}0.040^{* *} \\
(2.191)\end{array}$ & $\begin{array}{c}0.010 \\
(0.572)\end{array}$ & $\begin{array}{c}0.012 * * * \\
(4.037)\end{array}$ & $\begin{array}{c}0.009 * * * \\
(3.229)\end{array}$ & $\begin{array}{c}0.084 * * * \\
(6.447)\end{array}$ \\
\hline Constant & $\begin{array}{c}2.363 * * * \\
(0.045) \\
\end{array}$ & $\begin{array}{c}-2.189 * * * \\
(-12.349) \\
\end{array}$ & $\begin{array}{c}-0.391 * * * \\
(-15.971) \\
\end{array}$ & $\begin{array}{c}2.302 * * * \\
(62.299) \\
\end{array}$ & $\begin{array}{c}2.359 * * * \\
(66.422) \\
\end{array}$ & $\begin{array}{c}2.374 * * * \\
(65.278) \\
\end{array}$ \\
\hline Region fixed effects & Yes & Yes & Yes & Yes & Yes & Yes \\
\hline Firm fixed effects & Yes & Yes & Yes & Yes & Yes & Yes \\
\hline $\mathrm{R}^{2}$ & 0.6338 & 0.469 & 0.389 & 0.642 & 0.669 & 0.672 \\
\hline Sample size & 13024 & 13024 & 13024 & 13024 & 13024 & 13024 \\
\hline
\end{tabular}

Notes: The value in () is the $t$ statistic after correcting the heteroscedasticity; $* * * p<0.01 ; * * p<0.05$; $* \mathrm{p}<0.1$.

In column (2) of Table5, we examine the effect of different amounts of subsidy on the R\&D investment. A negative coefficient on interaction term $d s u b^{3 * d t}$ would indicate that the enterprises receiving huge-level subsidy have lower ratio of R\&D expenditure to total sales. Through the rentseeking activities, enterprises can obtain huge government subsidy income (subsidy income constitutes the part of company's excess profits), which obviously weakens the incentives for 
enterprises to obtain excess profits through $R \& D$ investment. We find a positive coefficient and statistically significant on the $d s u b^{2 *} d t$ variable, indicating that medium government subsidy helps enterprises increase their R\&D investment. $d s u^{l * d t}$ are not estimated to have a significant impact on R\&D investment.

Column (4)-(6) provides the stepwise regression results based on the fourth estimating equation of model (5). In column (4), the coefficient on the mediator variable rent is -0.369 and statistically significant at the $10 \%$ level, indicating the increase in rent-seeking costs significantly reduces the capacity utilization of enterprises. On the one hand, the rent-seeking cost, as a part of the enterprises' non-operating expenses, will inevitably squeeze the available funds to increase capacity utilization; on the other hand, the excess profits and social responsibilities generated by rent-seeking may drive the enterprise to further expand its production capacity rather than overcapacity removal. In column (5), Enterprises with larger R\&D investment having higher capacity utilization is supported by a positive and statistically significant coefficient on another mediator variable $R \& D$ variable.

Statistical evidence for rent-seeking cost, as well as R\&D investment mediating effect is strong, the absolute values of the estimated coefficients on the interaction term $d s u b^{3 *} d t$ in both column (4) and column (5) decrease compared with the column (1), and the absolute value in column (6) further decreases when introducing the above two median variables at the same time, indicating the mediating effect does exist. That is, the "rent-seeking" costs and the weakening of R\&D investment are important channels for huge government subsidy to reduce the capacity utilization.

\section{Summary}

This paper aims to assess the causal impact of government subsidy on the overcapacity of Chinese steel enterprises. In order to overcome the problem of selection bias and confounding bias, we use the propensity score matching method to find the most suitable non-subsidized enterprises (control group) for subsidized enterprises (treatment groups). We then construct the Difference-in-Difference model to identify the causal effects of government subsidy on the capacity utilization based on the matching samples. Finally, we apply an intermediary model to explore why huge-level subsidy reduce the capacity utilization.

In general, subsidy is not estimated to have a significant effect on the capacity utilization. When the amount of subsidy is divided into low-level, medium-level and huge-level according to the quantile value, we find that only medium-level subsidy increases the capacity utilization, while hugelevel government subsidy tends to worsen further overcapacity, but low-level subsidy has no significant impact on the overcapacity. Such estimated results are robustness to alternative observation period.

Then, the regression results of intermediary model provide support for rent-seeking cost, as well as R\&D investment mediating effect: enterprises with huge-level subsidy tend to increase rentseeking costs but reduce R\&D investment. An implication is that rent-seeking investment and the weakening of $R \& D$ incentives are the important channels for huge-level subsidy curbing the steel capacity utilization.

\section{Acknowledgements}

Project Supported by Humanities and Social Sciences Research Program of Chongqing Municipal Education Commission (Grant No. 17SKG199), and Doctoral Program of Chongqing Social Science Association (Grant No. 2017BS50).

\section{References}

[1]. Worrell, E. Advanced technologies and energy efficiency in the iron and steel industry in china. Energy for Sustainable Development, Vol.2 (1995) No. 4, p.27-40. 
[2]. Price, A. H. \&Christopher, B. Weld, et al. Unsustainable: Government Intervention and Overcapacity in the Global Steel Industry, Washington, DC, April, 2016,p.1-25.

[3]. Pindyck, R. S. Irreversible investment, capacity choice, and the value of the firm. Social Science Electronic Publishing, Vol.78(1988) No.5, p.969-985.

[4]. Fay, J. A., \& Medoff, J. L. Labor and output over the business cycle: some direct evidence. American Economic Review, Vol.75 (1985) No.4, p. 638-655.

[5]. Abel, A. B. (1983). Optimal investment under uncertainty. American Economic Review, Vol.73(1), p.228-233.

[6]. Stiglitz, J. E. Toward a general theory of wage and price rigidities and economic fluctuations. American Economic Review, Vol.89(2001) No.2, p.75-80.

[7]. Bulow, J., Geanakoplos, J., \& Klemperer, P. Holding idle capacity to deter entry. Economic Journal, Vol.95 (1985) No.377, p. 178-182.

[8]. Ogawa, H., \& Nishimori, A. Do firms always choose excess capacity?. Economics Bulletin, Vol.12 (2004) No.2, p.1-7.

[9]. Dixit, A. The role of investment in entry-deterrence. Economic Journal, Vol.90 (1980) No.357, p. 95-106.

[10]. Abadie, A., \& Imbens, G. W. Large sample properties of matching estimators for average treatment effects. Econometrica, Vol.74 (2010) No.1, p.235-267.

[11]. Heckman, J.; J. H. Ichimura.; P.E. Todd. Matching as an Econometric Evaluation Estimator: Evidence from Evaluating a Job Training Program. Review of Economic Studies, Vol.64 (1997) No.4, p.605-654.

[12]. Diebold, W., Howell, T. R., Noellert, W. A., Kreier, J. G., \& Wolff, A. W. Steel and the state: government intervention and steel's structural crisis. Foreign Affairs, Vol.68 (1988) No.2, p. 190-206.

[13]. Price, L., Sinton, J., Worrell, E., Phylipsen, D., Xiulian, H., \& Ji, L. Energy use and carbon dioxide emissions from steel production in china. Energy, Vol.27(2002) No.5, p. 429-446.

[14]. Blonigen, B. A., \& Wilson, W. W. Foreign subsidization and excess capacity. Journal of International Economics, Vol.80(2010) No. 2, p. 200-211.

[15]. Gwartney, J., Lawson, R., \& Holcombe, R. The size and functions of the government and economic growth, Joint Economic Committee, Washington, DC, Aprial 1998, P.1-33.

[16]. Hirota, S. A study of iron and steel subsidy. Kyoto University Economic Review, Vol.2 (1951). (51), p.1-47.

[17]. Morck, R., Sepanski, J., \& Bernard Yeung $\uparrow$. Habitual and occasional lobbyers in the U.S. steel industry: an em algorithm pooling approach. Economic Inquiry, Vol.39(2010) No.3, p.365378.

[18]. Shleifer, A., \& Vishny, R. W. Politicians and firms. Quarterly Journal of Economics, Vol.109(1994) No.4, p. 995-1025.

[19]. Lenway, S., Morck, R., \& Yeung, B. Rent seeking, protectionism and innovation in the american steel industry. Economic Journal, Vol.106(1996) No.435, p.410-421.

[20]. Murphy, K. M., Shleifer, A., \& Vishny, R. W.Why is rent-seeking so costly to growth?. American Economic Review, Vol.83(2010) No.2, p.409-414. 
[21]. Feenstra, R.; Li Z; Yu M. et al. Exports and credit constraints under incomplete information: theory and evidence from China. Journal of Financial Economic, Vol.96(2017) No.4, p. 729-744.

[22]. Olley, G. S., \& Pakes, A. The dynamics of productivity in the telecommunications equipment industry. Econometrica, Vol.64(1996) No.6, p.1263-1297.

[23]. Klein, L. R. Some theoretical issues in the measurement of capacity. Econometrica, Vol.28(1960).(2), p.272-286.

[24]. Morrison, C. J. On the economic interpretation and measurement of optimal capacity utilization with anticipatory expectations. Review of Economic Studies, Vol.52(1985) No.2, p.295-310.

[25]. Nelson, R. A. On the measurement of capacity utilization. Journal of Industrial Economics, Vol.37(1989) No.3, p.273-286.

[26]. Smith, J. A., \& Todd, P. E. Does matching overcome lalonde's critique of non-sexperimental estimators Journal of Econometrics, Vol.125 (2005) No.1, p.305-353. 